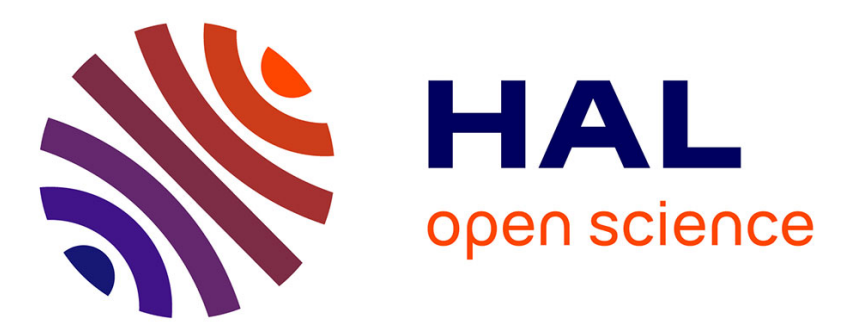

\title{
Active Hyperspectral Mid-Infrared Imaging Based on Widely Tunable QCL Laser
}

Chaimae El Fakir, Luiz Poffo, Bastien Billiot, Pascal Besnard, Jean-Marc

Goujon

\section{- To cite this version:}

Chaimae El Fakir, Luiz Poffo, Bastien Billiot, Pascal Besnard, Jean-Marc Goujon. Active Hyperspectral Mid-Infrared Imaging Based on Widely Tunable QCL Laser. 21st International Conference on Transparent Optical Networks (ICTON 2019), Jul 2019, Angers, France. pp.1-4, 10.1109/ICTON.2019.8840448 . hal-02382528

\section{HAL Id: hal-02382528 \\ https://hal.science/hal-02382528}

Submitted on 27 Nov 2019

HAL is a multi-disciplinary open access archive for the deposit and dissemination of scientific research documents, whether they are published or not. The documents may come from teaching and research institutions in France or abroad, or from public or private research centers.
L'archive ouverte pluridisciplinaire HAL, est destinée au dépôt et à la diffusion de documents scientifiques de niveau recherche, publiés ou non, émanant des établissements d'enseignement et de recherche français ou étrangers, des laboratoires publics ou privés. 


\title{
Active Hyperspectral Mid-Infrared Imaging Based on Widely Tunable QCL Laser
}

\author{
Chaimae El Fakir ${ }^{1}$, Luiz Poffo ${ }^{1}$, Bastien Billiot ${ }^{2}$, Pascal Besnard ${ }^{1}$, and Jean-Marc Goujon ${ }^{1}$ \\ ${ }^{1}$ Univ Rennes, CNRS, Institut FOTON - UMR 6082, F-22300 Lannion, France \\ ${ }^{2}$ Agro Innovation International-CMI, 35400 Saint-Malo, France \\ Tel: (029) 646 9146,e-mail: chaimae.elfakir@univ-rennes1.fr
}

\begin{abstract}
Thermal imaging and the recent availability of widely tunable infrared QCL lasers (Quantum Cascade Laser) allow us to propose an active hyperspectral imaging system operating in mid-infrared (MIR) band to obtain simultaneously large amounts of spatial and spectral information on the samples.

In order to evaluate more precisely the capacities of the active hyperspectral imaging, we propose a system composed of four powerful QCL tunable lasers (in order to cover 3-5 $\mu \mathrm{m}$ and $7-11 \mu \mathrm{m}$ wavelengths) and three cameras: a visible and near-infrared (NIR) range, a bolometer for $7-13 \mu \mathrm{m}$ range and an InSb cooled camera for $3-5 \mu \mathrm{m}$ range. We present the algorithm for image acquisition, image and data processing. Finally, we present and discuss some preliminary results using this system to characterize plant leaves under controlled growing conditions.
\end{abstract}

Keywords: hyperspectral imaging, mid-infrared, tunable QCL laser, plant monitoring, image processing.

\section{INTRODUCTION}

Multi/hyperspectral imaging is a method used for classifying and mapping materials according to their intrinsic characteristics. It combines spectroscopy and imaging techniques to extract simultaneously spectral and spatial signatures, where the system output consists in series of narrow band sub-images arranged across the reflectance spectrum, forming a hypercube data that can be acquired by four basic techniques: point scanning (whiskbroom), line scanning (push-broom), area scanning (spectral scanning) and snap-shot (non-scanning). [1] ,[2], [3].

Most multi/hyperspectral imaging system has been focusing on visible and near infrared (NIR) because of their mature technologies. However, the mid-infrared (MIR) portion of optical spectrum seems to contain valuable new information on some of the features needed to discriminate samples, for example samples with diseases or some contamination or for quality inspection [4]. The recent development of light sources and imaging systems in MIR allows the use of multi/hyperspectral MIR imaging in many new applications.

There are major differences in the nature of hypercube data obtained by tunable monochromatic light sources and continuous sources. Continuous or broadband sources are most often used with filters, where ambient light reflected from a scene is filtered in a specific wavelength band to form an image. The hypercube data contain as many images of the same scene as filters used to acquire them, as shown in Fig. 1a [1], [5], [6]. We can call this method "Passive Multispectral Imaging", because the light source normally is the ambient light. The main limitation of this method is the number of filters used to form the hypercube data. It should be noted that infrared tunable filters are recent technology that not yet mature [7].

The recent development of new tunable monochromatic light sources such as MIR quantum cascade laser (QCL) allows us to propose an active hyperspectral imaging with a small wavelength separation unit between each image. The result is a hypercube data that looks like a continuous wavelength variation, as shown in Fig. 1b. The term "active" means that the system is associated with a controlled artificial light source rather than the ambient radiation. QCLs are becoming commercially mature, but may require a multi-chip design to cover wide spectral ranges.
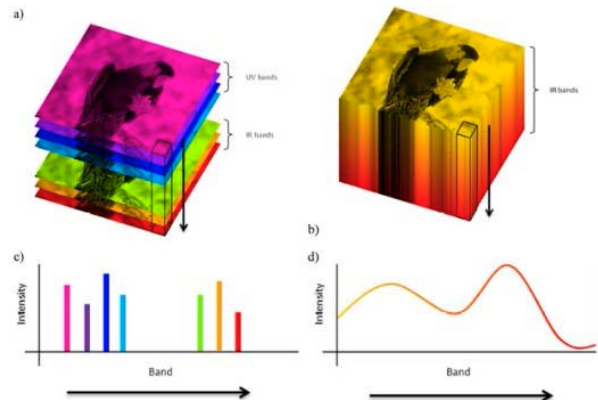

Figure 1. Hypercube data using: (a) wavelength filters and (b) using a tunable monochromatic light source; (c), (d) The intensity profiles for the pixels indicated in (a), (b), respectively [8]. 
As common limitations of such systems, one can mention noises associated to the source, to thermal variations of the scene, and to the detector. To overcome the latter one, cooling semiconductor detectors are often used. Uncooled bolometer detectors are balanced from their own temperature effects, but exhibit lower signal to noise ratio. Nevertheless, bolometer imaging detectors are costless and easy to use.

In this work, we present a complete experimental bench based on active hyperspectral imaging system in MIR, using four powerful QCL tunable lasers covering 3-5 $\mu \mathrm{m}$ and $7-11 \mu \mathrm{m}$ wavelengths. Using an optical system, the laser beam was shaped to illuminate a large scene. The acquisition technique used is a snap-shot using different cameras (detectors). To our knowledge, this is the unique bench with these characteristics. Finally, we propose an image treatment and data processing for an example of application plant leaf characterization.

\section{METHOD}

The hypercube data is acquired using an experimental bench at laboratory composed, in a simplistic terms, by a laser source, a mirror system to enlarge the laser beam, a Lambertian reference, the sample to characterize and the cameras, as shown in Fig. 2a. Each element is described in more details below.

(a)

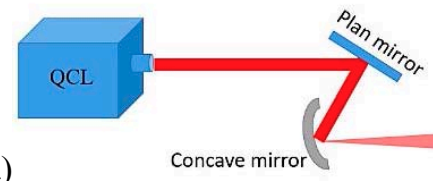

Concave mirror

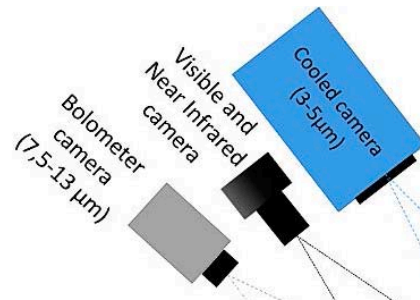

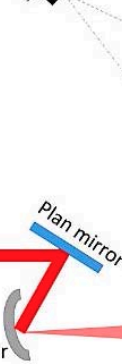

(b)

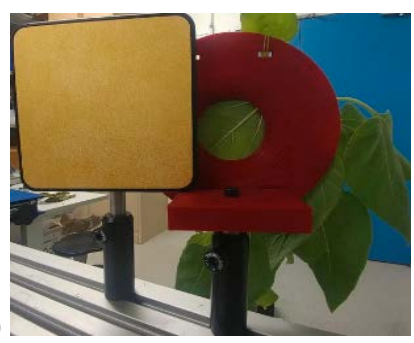

(c)

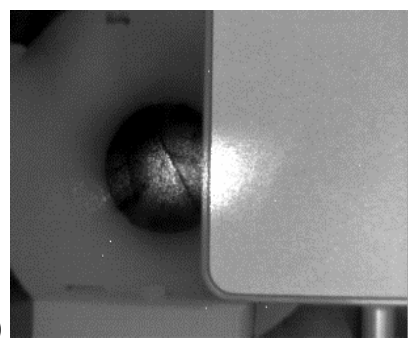

Figure 2: (a) Schematic of the experimental bench for active hyperspectral imaging; (b) Detail of the diffusing screen and sample support; (c) An example of MIR image.

The laser source is a set of 4 tunable QCL (Daylight MIRCAT), operating in MIR spectral range. The first QCL (QCL1), tunable from 3.9 to $4.7 \mu \mathrm{m}$, operates in pulsed mode, with a duty cycle quoted up to $10 \%$. Repetition rate can range up to $1 \mathrm{MHz}$, and the pulse width can be varied from $40 \mathrm{~ns}$ to $500 \mathrm{~ns}$. The maximum average output power is $11 \mathrm{~mW}$. The three others QCLs modules are: QCL2 tunable from 6.73 to $7.75 \mu \mathrm{m}$, QCL3 tunable from 7.69 to $8.64 \mu \mathrm{m}$ and QCL4 tunable from 8.39 to $11 \mu \mathrm{m}$. They operate in continuous mode $(\mathrm{CW})$, with a maximum output power up to $350 \mathrm{~mW}$. For each module, linewidths are less than $10 \mathrm{~nm}$. For the experimental bench, in pulsed mode, the laser operates with $5 \%$ as duty cycle, repetition range at $100 \mathrm{kHz}$ and $500 \mathrm{~ns}$ for the pulse width.

The Fig. 3 shows the normalized power spectrum recorded by the cameras after diffuse reflection on a wideband IR Lambertian reference gold plane (IRL).

The laser beam is expanded with appropriate gold mirror system to achieve a $5 \mathrm{~cm}$ diameter illumination, which is applied simultaneously to the sample and to IRL (Fig. 2b).

The observation system is composed by two standard thermal cameras in different spectral bands. The first camera is a FLIR SC5000, with a InSb detector that needs to be cooled. The spectral band is from $3 \mu \mathrm{m}$ to $5 \mu \mathrm{m}$. The second one is a FLIR A65, with a bolometer detector. It doesn't need to be cooled and the spectral band is from $7.5 \mu \mathrm{m}$ to $13 \mu \mathrm{m}$. To complete the observation system, we use a visible / NIR camera with a highresolution CMOS detector to provide a spatial location reference used in image processing. Technical specifications of all cameras are summarized in Table 1.

Table 1. Properties of different cameras of the observation system.

\begin{tabular}{|l|c|c|c|c|c|c|}
\hline Detector type & $\begin{array}{c}\text { Spectral } \\
\text { band }(\mathbf{n m})\end{array}$ & $\begin{array}{c}\text { Spatial } \\
\text { resolution }\end{array}$ & $\begin{array}{c}\text { Pixel size } \\
(\boldsymbol{\mu m})\end{array}$ & $\begin{array}{c}\text { Frame rate } \\
(\text { FPS })\end{array}$ & $\begin{array}{c}\text { Temperature } \\
\text { range }\left({ }^{\circ} \mathbf{C}\right)\end{array}$ & $\begin{array}{c}\text { Integration } \\
\text { time }\end{array}$ \\
\hline CMOS & $400-1000$ & $2048 \times 1536$ & 3.45 & 38 & -10 to 60 & $24 \mu \mathrm{s}$ to $1 \mathrm{~s}$ \\
\hline InSb & $3000-5000$ & $320 \times 256$ & 30 & 170 & 5 to 300 & $3 \mu \mathrm{s}$ to $20 \mathrm{~ms}$ \\
\hline Bolometer & $7500-13000$ & $640 \times 512$ & 17 & 30 & -25 to 135 & - \\
\hline
\end{tabular}


Each camera can see the sample and a part of the IRL. The IRL image is used as the incidence power reference. The observation system performs a sequence of shots (one shot for each set wavelength). An image without laser illumination is taken between each wavelength change. This image is used to subtract the background of the scene. For a wavelength step of $1 \mathrm{~nm} 9234$ images have to be processed. To obtain the sample spectra, the algorithm selects an area from the sample and from the IRL and calculate the average intensity from all pixels inside each selected area. The result is a normalized spectrum with the IRL average intensity reference. A Machine Learning algorithm is being written for the discrimination of the samples with the spectra results.

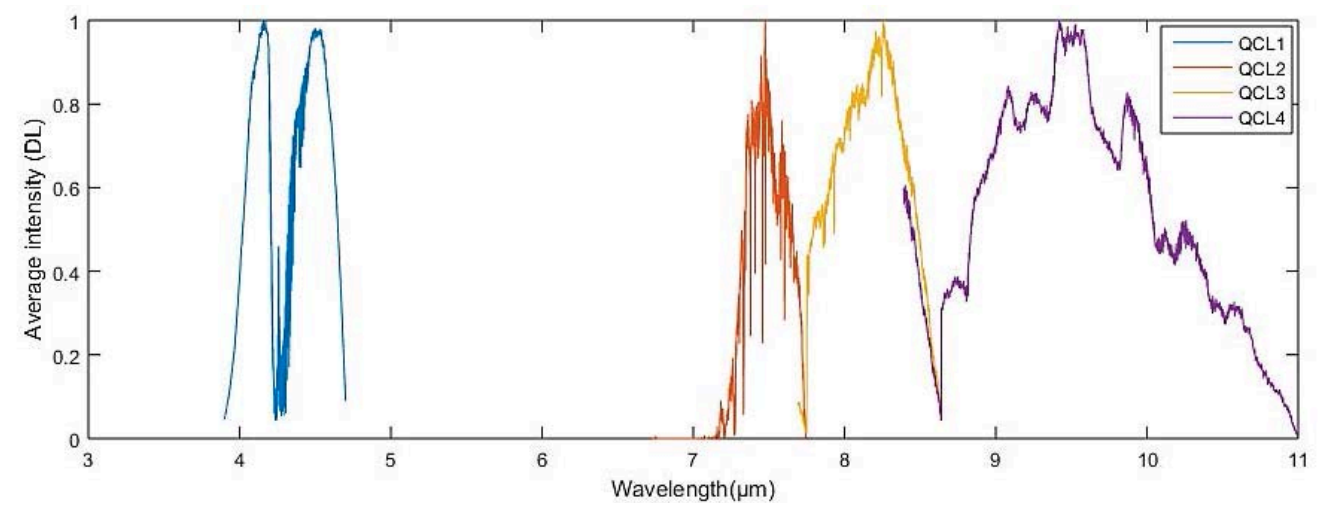

Figure 3. Normalized power spectrum as seen by infrared cameras. The power spectrum of QCL1 from $3.9 \mu \mathrm{m}$ to $4.7 \mu \mathrm{m}$ is obtained in pulsed mode by FLIR SC5000 camera. The other three spectra of QCL2, QCL3 and QCL4 are obtained by FLIR A65 camera in continuous mode.

\section{RESULTS}

After laser characterization, the proposed system was tested to extract spectral reflectance of growing plant leaf on surface of $5 \mathrm{~cm}$ diameter. The graphs below, present the first mean spectrum obtained. The Fig. 4a shows the reflectance rate of leaf from $3.9 \mu \mathrm{m}$ to $4.7 \mu \mathrm{m}$ with spectral resolution of $1 \mathrm{~nm}$. We notice a variability in reflectance rate between 0.2 and 0.5 , whereas in the zone between $4.2 \mu \mathrm{m}$ and $4.3 \mu \mathrm{m}$, the $\mathrm{CO}_{2}$ absorption can be found. The spectral region between $3.9 \mu \mathrm{m}$ and $4.7 \mu \mathrm{m}$ can allows to characterise water content of leaf [9], [10].

Figure $4 \mathrm{~b}$, show mean spectrum of leaf in large band from $7.5 \mu \mathrm{m}$ to $11 \mu \mathrm{m}$. The leaf reflected less in this spectral range, we can notice in graph that reflectance rate change between 0.02 and 0.4 . The spectral range between $7.5 \mu \mathrm{m}$ and $11 \mu \mathrm{m}$ can be used for species identifications [11], [12].

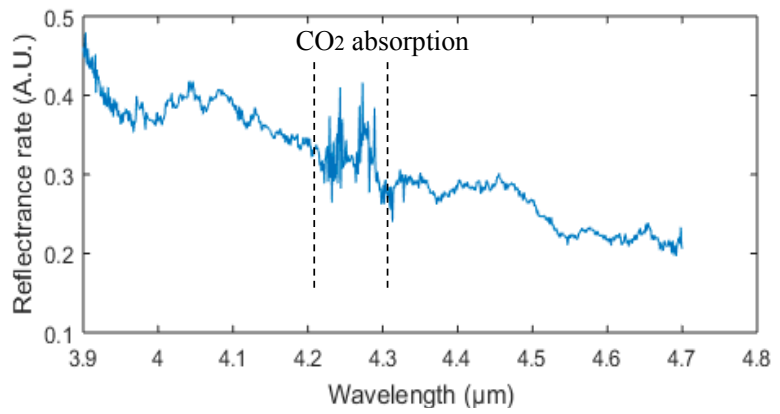

(a)

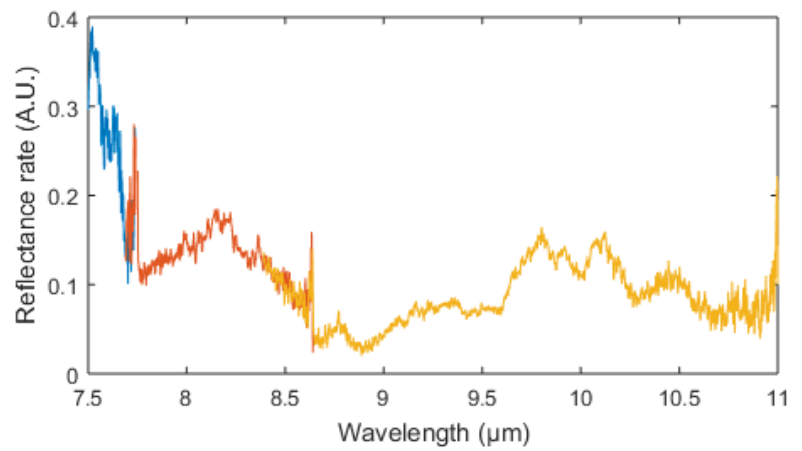

(b)

Figure 4. Mean spectra of plant leaf: (a) Spectra from $3.9 \mu \mathrm{m}$ to $4.7 \mu \mathrm{m}$, the region between $4.2 \mu \mathrm{m}$ and $4.3 \mu \mathrm{m}$ is affected by $\mathrm{CO}_{2}$; (b) Spectra from $7.5 \mu \mathrm{m}$ to $11 \mu \mathrm{m}$.

\section{DISCUSSION}

The reflectance rate spectra of leaf are calculated by determining the ratio between average intensity of measurement area on sample and on IRL, to eliminate the spectral influence of the source. Since illumination intensity is not uniform over the sample, spectra should also be normalized before comparison.

The effects of the Relative Intensity Noise (RIN) associated to QCL source can be automatically compensated, by illuminating simultaneously the sample and the IRL and acquiring a single picture. However, the effects of beam pointing fluctuation remain. On the other hand, the noise associated to the detector can be reduced by taking several pictures of the scene, and calculating the average value of each pixel.

Since the laser exhibits coherent monochromatic behavior, speckle effects can be observed on the picture. They appear to be stable, with an average size of 1 pixel. Thus, to eliminate the local variations, spatial average on region of interest (ROI) can be calculated. The size of the square ROI was 6x6 pixels. It should be noticed that 
speckle patterns may also provide useful information on samples such as distance, or depolarization characteristics. This will be investigated in further works.

During MIR measurement, an intensity drift of the background can be observed. This may be due to thermal variation of the background, and to the energy transfer from the laser to the sample. This can be easily compensated by acquiring a reference picture as often as necessary.

\section{CONCLUSIONS AND FURTHER WORKS}

In this study, we present a preliminary results of an active hyperspectral imaging system operating in midinfrared spectral range, using a tunable laser modules exhibits a strong illuminating power up to $11 \mathrm{~mW}$ in pulsed mode between $3.9 \mu \mathrm{m}$ and $4.7 \mu \mathrm{m}$ spectral range, and up to $350 \mathrm{~mW}$ in continuous mode between $7.5 \mu \mathrm{m}$ and $11 \mu \mathrm{m}$. This allows the MIR active imaging spectrometer to analyze large samples with a field of view up to $5 \mathrm{~cm}$ diameter. Wavelength sweep step can be set as small as $1 \mathrm{~nm}$, with a laser linewidth less than $10 \mathrm{~nm}$ allows to obtain a hypercube like a continuous wavelength variation.

During this preliminary study, the spectra of averaged zones of plant leaves was obtained, and will be help to characterize health status of different plants before using image processing techniques to find spatial signatures of samples.

\section{REFERENCES}

[1] P. Mishra, M. S. M. Asaari, A. Herrero-Langreo, S. Lohumi, B. Diezma, and P. Scheunders, "Close range hyperspectral imaging of plants: A review," Biosyst. Eng., vol. 164, pp. 49-67, Dec. 2017.

[2] J. Behmann, J. Steinrücken, and L. Plümer, "Detection of early plant stress responses in hyperspectral images - ScienceDirect," ISPRS Journal of Photogrammetry and Remote Sensing, vol. 93, pp. 98-111, Jul. 2014.

[3] M. A. Lara, L. Lleó, B. Diezma-Iglesias, J. M. Roger, and M. Ruiz-Altisent, "Monitoring spinach shelflife with hyperspectral image through packaging films," J. Food Eng., vol. 119, no. 2, pp. 353-361, Nov. 2013.

[4] M. F. B. Acevedo, "Infrared spectroscopy of leaf traits: Detecting plant stress and identifying plant species," 2018.

[5] J. Huang, H. Liao, Y. Zhu, J. Sun, Q. Sun, and X. Liu, "Hyperspectral detection of rice damaged by rice leaf folder (Cnaphalocrocis medinalis)," Comput. Electron. Agric., vol. 82, pp. 100-107, Mar. 2012.

[6] J. R. Simard and F. Christnacher, "Imagerie hyperspectrale active appliquée à la caractérisation des sols contaminés au TNT," 2006.

[7] J. Lin et al., "Electrically tunable infrared filter based on a cascaded liquid-crystal Fabry-Perot for spectral imaging detection," Appl. Opt., vol. 56, no. 7, pp. 1925-1929, Mar. 2017.

[8] M. Hermes et al., "Mid-IR hyperspectral imaging for label-free histopathology and cytology," J. Opt., vol. 20, no. 2, p. 023002, Jan. 2018.

[9] B. R. Da Luz and J. K. Crowley, "Spectral reflectance and emissivity features of broad leaf plants: Prospects for remote sensing in the thermal infrared $(8.0-14.0 \mu \mathrm{m})$," Remote Sens. Environ., vol. 109, no. 4, pp. 393-405, 2007.

[10] M. F. Buitrago, T. A. Groen, C. A. Hecker, and A. K. Skidmore, "Changes in thermal infrared spectra of plants caused by temperature and water stress,” ISPRS J. Photogramm. Remote Sens., vol. 111, pp. 22-31, Jan. 2016.

[11] B. Ribeiro da Luz and J. K. Crowley, "Identification of plant species by using high spatial and spectral resolution thermal infrared $(8.0-13.5 \mu \mathrm{m})$ imagery," Remote Sens. Environ., vol. 114, no. 2, pp. 404-413, Feb. 2010.

[12] S. Ullah, M. Schlerf, A. K. Skidmore, and C. Hecker, "Identifying plant species using mid-wave infrared $(2.5-6 \mu \mathrm{m})$ and thermal infrared $(8-14 \mu \mathrm{m})$ emissivity spectra," Remote Sens. Environ., vol. 118, pp. 95-102, Mar. 2012. 